Tropical Journal of Pharmaceutical Research October 2019; 18 (10): 2019-2024

ISSN: $1596-5996$ (print); 1596-9827 (electronic)

(C) Pharmacotherapy Group, Faculty of Pharmacy, University of Benin, Benin City, 300001 Nigeria.

\title{
Effect of early exogenous supplementation of rhIGF-1 on oxygen-induced retinopathy in a mice model of prematurity, and on expressions of IGF-1 and VEGF
}

\author{
Xiangjun Wu, Hui Ye, Qiao Cai, Yuanxiang Ke, Danying Wang* \\ Department of Pediatrics, Taizhou First People's Hospital, Taizhou 318020, People's Republic of China
}

*For correspondence: Email: zjchs7@163.com

Sent for review: 17 July 2019

Revised accepted: 29 September 2019

\begin{abstract}
Purpose: To investigate the effect of early exogenous supplementation of recombinant human insulinlike growth factor (rhlGF-1) on oxygen-induced mouse model of retinopathy of prematurity (ROP).

Methods: Three groups of healthy SPF grade C57BL/6 mice were used in this study, with 20 mice in each group. Hyperoxia saline (HS) and hyperoxia rhIGF-1 (HrGF) groups were placed in a closed oxygen chamber for one week and returned to the normal environment on the 15th day. The hyperoxia rh/GF-1 (HrGF) group was intraperitoneally injected with rh/GF-1 (1.5 mg/kg), while mice in high-oxygen saline (HS) group received normal saline. The air group (AG) was untreated. Changes in retinal blood vessel distributions, expression levels of serum IGF-1 and VEGF, and retinal IGF-1 and VEGF were determined.

Results: On day 20, pronounced neo-vascularization was observed, but the distribution was disordered. Serum IGF-1 levels in AG and HrGF were significantly higher than that in HS group, but VEGF level was lower in HS mice $(p<0.05)$. VEGF level in hyperoxia rhlGF-1 group on days 11 and 15 decreased, relative to control value, while retinal IGF-1 and VEGF in AG and hyperoxia rhIGF-1 mice were elevated, relative to corresponding values in HS mice $(p<0.05)$.

Conclusion: Early exogenous supplementation of rh/GF-1 exerts a therapeutic effect on ROP. Thus, rh/GF-1 may be a potential drug regimen for ROP in clinics.
\end{abstract}

Keywords: Oxygen-induced retinopathy, rhIGF-1, Premature infants, IGF-1, VEGF

\begin{abstract}
This is an Open Access article that uses a fund-ing model which does not charge readers or their institutions for access and distributed under the terms of the Creative Commons Attribution License (http://creativecommons.org/licenses/by/4.0) and the Budapest Open Access Initiative (http://www.budapestopenaccessinitiative.org/read), which permit unrestricted use, distribution, and reproduction in any medium, provided the original work is properly credited.

Tropical Journal of Pharmaceutical Research is indexed by Science Citation Index (SciSearch), Scopus, International Pharmaceutical Abstract, Chemical Abstracts, Embase, Index Copernicus, EBSCO, African Index Medicus, JournalSeek, Journal Citation Reports/Science Edition, Directory of Open Access Journals (DOAJ), African Journal Online, Bioline International, Open-J-Gate and Pharmacy Abstracts
\end{abstract}

\section{INTRODUCTION}

Retinopathy of prematurity (ROP) is also known as post-lens fiber hyperplasia (RLF). It refers to immature retinal blood vessels in premature infants which result in retinal neovascularization and fibrous tissue proliferation, the major causes of blindness in children [1,2]. The incidence of ROP in China is increasing year by year, and it seriously affects quality of life of the patients. Studies have found that ROP is closely related to premature birth, low birth weight and high concentration of oxygen. Exogenous recombinant human insulin-like growth factor-1 (rhlGF-1) is a multifunctional cell proliferation regulator that induces and promotes cell differentiation [3]. 
Vascular endothelial growth factor (VEGF) promotes angiogenesis and inhibits the proliferation of abnormal neovascularization in the eye [4]. At present, ROP is treated through direct inhibition of angiogenesis. However, apart from not providing a fundamental solution to ROP, this treatment results in irreparable damage to the patient [5]. In the present study, the effects of early exogenous rhlGF-1 supplementation on oxygen-induced mice model of ROP and the expressions of IGF-1 and VEGF were investigated.

\section{EXPERIMENTAL}

\section{Laboratory animals}

Sixty newly-littered and healthy SPF grade C57BL/6 mice pups weighing $16 \pm 4 \mathrm{~g}$ were provided by Shanghai Ruitai Moss Biotechnology Co. Ltd. [production license SCXK (Shanghai) 2016-0001]. The pups were fed freely in our laboratory by lactating does, at a temperature of $20 \pm 3{ }^{\circ} \mathrm{C}$ and humidity of $58 \pm 12 \%$. Feed and drinking water were freely provided.

This work was approved by the Animal Ethical Committee of Taizhou First People's Hospital (approval no. 20180911), and was implemented in line with "Principles of Laboratory Animal Care" [6].

\section{Instruments and reagents}

The instruments and reagents used (with their suppliers and models/specifications shown in brackets) were: Oxygen box (US SHELLAB Company, model: BACTRO X-2); Oxygen concentration analyzer (Shenzhen Shandun Technology Co. Ltd, model: Smart Pro10); Oxygen cylinder, nitrogen bottle (Shandong Huasheng High Pressure Container Co. Ltd, specification: 40 L); Sanmu microscope (Shanghai Yuanhao Testing Equipment Co. Ltd., model: YRS-32); Constant temperature water bath (Shanghai Hetian Scientific Instrument Co. Ltd, specification: HH-US), and refrigerator (Qingdao Haier Group, model: BCD-470WDPG).

Others were immunohistochemistry kit (Shanghai Meixuan Biotechnology Co. Ltd); $0.9 \%$ sodium chloride injection (Chengdu Qingshan Likang Pharmaceutical Co. Ltd, specification: $100 \mathrm{~mL}$ : $0.9 \mathrm{~g}$, production batch number: 2011120917); rhIGF-1 (Jiangsu Prosci Biotechnology Co., Ltd., Brand: AbZyme); Rabbit IGF-1 Monoclonal Antibody (Beijing Yiqiao Shenzhou Technology Co. Ltd, Specification: $50 \mu \mathrm{g}$ ); Mouse VEGF Monoclonal Antibody (PeproTech, USA, specifications: $500 \mu \mathrm{g}$ ); IGF-1 test kit (Qingdao
Jieshikang Biotechnology Co., Ltd., specification: 48T); VEGF test kit (Shanghai Enzyme Technology Co. Ltd, specification: 48T), and ketamine hydrochloride injection (Zhejiang Jiu Xu Pharmaceutical Co. Ltd, approval number: National Medicine quasi-word H20173609, specification: $10 \mathrm{~mL}: 0.1 \mathrm{~g}$ ).

\section{Mouse pup groups}

Sixty (60) pups were randomly divided into three groups, with the random number table method: air group (AG), hyperoxic saline (HS) group, and hyperoxia rhlGF-1 HrGF) group (20 pups per group). The mice were raised together with lactating does. The HS saline mice and the hyperoxia rhIGF-1 mice groups were placed in a closed oxygen chamber. The air inlet was connected to an oxygen cylinder and a nitrogen bottle, and the outlet was connected to an oxygen concentration analyzer to maintain the oxygen partial pressure at $74 \pm 1 \%$ or thereabout. The controlled oxygen chamber temperature was maintained at $25 \pm 2{ }^{\circ} \mathrm{C}$, and the humidity was $57 \pm 6 \%$.

The HS and HrGF mice were placed in oxygen box for one week, and the litter, the lactating doe and the feed were changed daily. On the $15^{\text {th }}$ day, they were returned to the normal breeding environment with a relatively low oxygen state so as to establish an ROP model. The hyperoxia rhIGF-1 group was intraperitoneally injected with $1.5 \mathrm{mg} / \mathrm{kg}$ rhIGF-1, while the hyperoxia saline group was intraperitoneally injected with an equivalent volume of normal saline in place of rhIGF-1. The air group was normally reared without treatment. All mice were sacrificed at the end of the experiment.

\section{Study indices}

Five mice in each group were weighed and intraperitoneally injected with $1-2 \mathrm{mg} / \mathrm{kg}$ ketamine hydrochloride for anesthesia on the $7^{\text {th }}$, $11^{\text {th }}, 15^{\text {th }}$, and $20^{\text {th }}$ days. The eyeballs were removed and fixed in $5 \%$ formaldehyde so as to remove the cornea, lens, and vitreous humor tissues. The retina was separated to avoid damage to the optic papilla. It was rinsed after staining, and the distribution characteristics of retinal blood vessels were examined.

During the removal of eyeball from the mice, 1 $\mathrm{mL}$ of blood was taken from each mouse, and the serum obtained after centrifugation was used for the assay of IGF-1 and VEGF. The levels of serum IGF-1 and VEGF were determined using enzyme linked immunosorbent assay (ELISA). 
The expressions of IGF-1 and VEGF in the retina were determined using immunohistochemistry.

\section{Statistical analysis}

Statistical analysis was performed using SPSS21.0 software package. Statistical comparison of measurement data was carried out with independent sample $t$-test, while chi square test was used for comparison of count data. Ranking data were compared with the Ridit test. Statistical significance was fixed at $p<0.05$.

\section{RESULTS}

\section{Body weight changes in mice}

On the $7^{\text {th }}$ day, there was no significant difference in body weight amongst the groups ( $p$ $>0.05$ ). However, on days 11,15 and 20 , the mice in the hyperoxia saline group had the lowest body weight, and at the same period, body weight of the high oxygen rhIGF-1 mice differed significantly from that of hyperoxia saline group $(p<0.05)$. In contrast, body weight was comparable between the air and hyperoxia rhIGF-1 mice groups on day $11(p>0.05)$. However, on days 15 and 20, the difference between the two groups was statistically significant $(p<0.05)$. These results are shown in Table 1.

Table 1: Mouse body weight changes ( $g$; mean \pm SD, $\mathrm{n}=5$ )

\begin{tabular}{lcccc}
\hline Group & Day 7 & Day 11 & Day 15 & Day 20 \\
\hline Air & $5.95 \pm$ & $7.84 \pm$ & $12.68 \pm$ & $16.54 \pm$ \\
Hyperoxia & 0.46 & 0.93 & 1.38 & 0.98 \\
saline & $0.54 \pm$ & $6.97 \pm$ & $8.79 \pm$ & $10.29 \pm$ \\
Hyperoxia & $6.02 \pm$ & $7.93 \pm$ & 1.21 & 0.79 \\
rhlGF-1 & 0.42 & 0.79 & 0.95 & $13.08 \pm$ \\
$F$ & 0.43 & 9.06 & 5.15 & 2204 \\
$P$-value & 0.651 & $<0.001$ & $<0.001$ & $<0.001$ \\
\hline
\end{tabular}

\section{Vascular distribution characteristics of mice}

On days 15 and 20 , retinal blood vessels in the air group were basically mature and evenly distributed, and on day 15, the retinal vessel diameter in the HS mice group was markedly thinner and unevenly distributed, showing wide occlusion areas. On the $20^{\text {th }}$ day, extensive neovascularization was present, but the distribution was disordered. In addition, the retinal vessel diameter and blood vessel distribution in the hyperoxia rhIGF-1 group were similar to those in the air group. These results are shown in Figures $1 \mathrm{~A}, 1 \mathrm{~B}$ and $1 \mathrm{C}$, and in Figures $2 \mathrm{~A}, 2 \mathrm{~B}$ and $2 \mathrm{C}$.
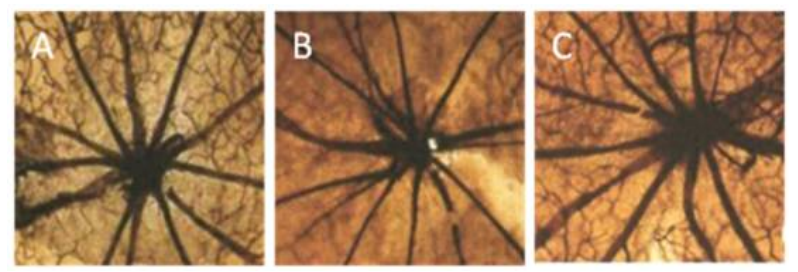

Figure 1: Distribution of retinal blood vessels in each group on day 15. A: air group; B: high-oxygen saline group; C: high-oxygen rhlGF-1 group

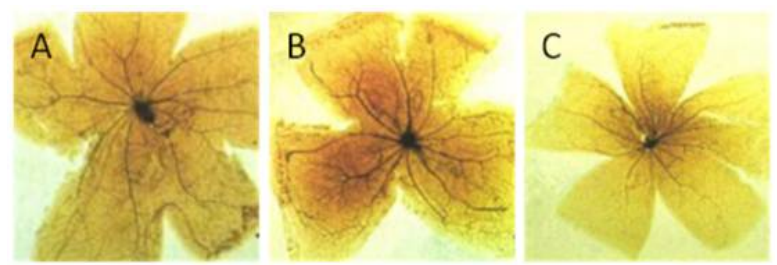

Figure 2: Distribution of retinal blood vessels in each group on day 20. Note: A, air group; B, high-oxygen saline group; $\mathrm{C}$, high-oxygen rhIGF-1 group

\section{Serum IGF-1 and VEGF levels in mice}

As the mice aged, the serum IGF-1 level gradually increased, with the air group showing the fastest increase, followed by the hyperoxia rhIGF-1 group, while the hyperoxic saline group was the slowest. In contrast, VEGF levels gradually decreased with age, and the hyperoxic saline group decreased the fastest, while the decrease in the air group was the slowest. However, after 15 days, VEGF level in the hyperoxic saline group increased rapidly, while the VEGF level in the hyperoxia rhIGF-1 group increased only slightly. On the day 7 , there were no significant differences in levels of IGF-1 and VEGF amongst the groups $(p>0.05)$.

On days 11 and 15, the serum levels of IGF-1 and VEGF in AG and the HrGF mice groups were markedly elevated, relative to their corresponding levels in HS mice. On the $20^{\text {th }}$ day, serum IGF-1 levels were markedly higher in $A G$ and HrGF mice groups than in HS mice, but the VEGF level was significantly lower than that in the hyperoxia saline group $(p<0.05)$. On days 11,15 and 20 , although serum IGF-1 of the hyperoxia rhIGF-1 group was less than control value, the values were comparable $(p>0.05)$. The VEGF level of hyperoxia rhIGF-1 group on days 11 and 15 were markedly lower than that in the hyperoxia saline group $(p<0.05)$. Serum VEGF level of hyperoxia rhIGF-1 group was lower than that of the control group on day 20, but the two values were comparable $(p>0.05)$. These results are shown in Table 2. 
Table 2: Serum IGF-1 and VEGF levels of mice (mean \pm SD)

\begin{tabular}{lcccccc}
\hline Group & Time & Air group & $\begin{array}{c}\text { Hyperoxia saline } \\
\text { group }\end{array}$ & $\begin{array}{c}\text { Hyperoxia rhIGF- } \\
\text { 1 group }\end{array}$ & $\boldsymbol{t}$ & $\boldsymbol{P}$-value \\
\hline \multirow{2}{*}{ IGF-1 } & Day 7 & $22.47 \pm 7.91$ & $22.51 \pm 4.49$ & $23.41 \pm 6.92$ & 0.03 & 0.968 \\
$(\mathrm{n}=5)$ & Day 11 & $64.67 \pm 11.66$ & $28.97 \pm 3.19$ & $59.03 \pm 13.68$ & 16.57 & $<0.001$ \\
& Day 15 & $74.12 \pm 12.58$ & $39.71 \pm 8.42$ & $67.64 \pm 13.87$ & 11.91 & 0.001 \\
& Day 20 & $90.58 \pm 11.45$ & $53.51 \pm 9.84$ & $83.82 \pm 6.79$ & 21.33 & $<0.001$ \\
VEGF & Day 7 & $2093.25 \pm 224.41$ & $2021.48 \pm 202.44$ & $2030.89 \pm 213.27$ & 0.17 & 0.848 \\
$(\mathrm{n}=5)$ & Day 11 & $1748.74 \pm 172.59$ & $610.09 \pm 114.11$ & $1306.26 \pm 181.12$ & 65.36 & $<0.001$ \\
& Day 15 & $1295.74 \pm 148.83$ & $332.66 \pm 49.88$ & $812.98 \pm 139.08$ & 79.08 & $<0.001$ \\
& Day 20 & $820.98 \pm 109.43$ & $1744.83 \pm 136.55$ & $820.03 \pm 148.84$ & 120.45 & $<0.001$ \\
\hline
\end{tabular}

Table 3: Retinal expressions of IGF-1 and VEGF in mice (mean \pm SD)

\begin{tabular}{lccccc}
\hline Group & Air group & $\begin{array}{c}\text { Hyperoxia saline } \\
\text { group }\end{array}$ & $\begin{array}{c}\text { Hyperoxia rhIGF-1 } \\
\text { group }\end{array}$ & $\boldsymbol{t}$ & $\boldsymbol{P}$-value \\
\hline & $0.13 \pm 0.03$ & $0.13 \pm 0.05$ & $0.12 \pm 0.03$ & 0.23 & 0.794 \\
IGF-1 $(\mathrm{n}=10)$ & $0.23 \pm 0.04$ & $0.14 \pm 0.03$ & $0.22 \pm 0.05$ & 14.61 & $<0.001$ \\
& $0.24 \pm 0.03$ & $0.15 \pm 0.04$ & $0.23 \pm 0.03$ & 21.47 & $<0.001$ \\
& $0.31 \pm 0.04$ & $0.18 \pm 0.03$ & $0.28 \pm 0.05$ & 23.56 & $<0.001$ \\
VEGF & $0.39 \pm 0.07$ & $0.36 \pm 0.06$ & $0.38 \pm 0.07$ & 0.52 & 0.599 \\
$(\mathrm{n}=10)$ & $0.33 \pm 0.03$ & $0.17 \pm 0.04$ & $0.27 \pm 0.06$ & 32.13 & $<0.001$ \\
& $0.26 \pm 0.05$ & $0.12 \pm 0.03$ & $0.21 \pm 0.03$ & 35.12 & $<0.001$ \\
& $0.21 \pm 0.03$ & $0.31 \pm 0.02$ & $0.22 \pm 0.03$ & 41.36 & $<0.001$ \\
\hline
\end{tabular}

\section{Expressions of IGF-1 and VEGF in retina of mice}

As the mice aged, the level of retinal IGF-1 gradually increased, with the increase being fastest in $A D$ mice, followed by HrGF mice. The hyperoxia saline group was the slowest. In contrast, VEGF level gradually decreased, and the decrease was slowest in the hyperoxic saline group, and fastest in the air group. On day 15, VEGF level of the mice in the hyperoxia group was rapidly increased, while in the hyperoxia rhIGF-1 group, VEGF was only slightly increased. On the $7^{\text {th }}$ day, the expressions of IGF-1 and VEGF were comparable amongst the three groups $(p>0.05)$. However, on days 11 and 15, retinal IGF-1 and VEGF levels in the air and hyperoxia rhIGF-1 groups were markedly elevated, when compared with levels in HS mice.

On day 20, retinal IGF-1 levels in $A G$ and hyperoxia rhIGF-1 group were markedly higher than IGF-1 in hyperoxia mice, and the VEGF level was markedly less than that in the hyperoxia group $(p<0.05)$. On days 11,15 and 20 , retinal IGF-1 levels in the hyperoxia rhIGF-1 control groups were comparable $(p>0.05)$. The VEGF levels in the hyperoxia rhIGF-1 group on days 11 and 15 were significantly lower than those in the control group $(p<0.05)$. There was no significant difference between the levels of retinal VEGF in the hyperoxia rhIGF-1 group and the control group on day $20(p>0.05)$. These results are presented in Table 3.

\section{DISCUSSION}

Retinopathy of prematurity (ROP) occurs in premature infants with low birth weight and longterm oxygen inhalation, whose fibroangioma of the non-vascularized retina develops and contracts, leading to retinal detachment and blindness $[7,8]$. In the present study, newlylittered mice pups aged one week were exposed to high-oxygen environment for a period of time and then returned to the normal environment for further feeding. The results showed that mice in the hyperoxia saline group had the lowest body weight on days 11, 15 and 20. There were significant differences in body weight between the high-oxygen rhIGF-1 group and the hyperoxia saline group, but there was no significant difference in body weight between the air group and the hyperoxia rhIGF-1 group on day 11.

However, body weight differed markedly between mice in both groups on days 15 and 20. Retinal blood vessels in the air group were basically mature and evenly distributed on days 15 and 20. On day 15 , retinal vessel diameter of the mice in the hyperoxia group was significantly thinner and unevenly distributed, showing a wide occlusion area, and on day 20, intensive neovascularization was evident, although the distribution was disordered. On day 15 , retinal vessel diameter and blood vessel distribution in the hyperoxia rhIGF-1 group and the air group were comparable. These results indicate that early exogenous supplementation of rhIGF-1 
promoted mice growth and significantly reduced angiogenesis.

Studies have shown that the incidence of ROP may be related to a variety of cytokines. In normal people, pro-angiogenic factors and angiogenesis inhibitors are in a relatively balanced state. However, in ROP patients, this homeostasis is impaired due to predominance of pro-angiogenic factors, resulting in enhanced neovascularization rate [9]. It is known that VEGF is a homodimeric protein and a specific heparin-binding growth factor for vascular endothelial cells, and that it effectively promotes angiogenesis [10]. Some researchers are of the view that the production of ROP is closely related to oxygen concentration [11]. Due to the fact that the retina of premature infants is underdeveloped, their retinal blood vessels stop growing or grow at reduced rates at high oxygen concentrations. However, once the hyperoxia condition is removed, the retina reverts to a relatively low oxygen state, leading to significant increases in VEGF levels which ultimately lead to ROP [12].

It has been reported that VEGF levels significantly higher than normal promote abnormal blood vessels in the retina and vitreous humor [13]. Premature infants have immature lungs. High oxygen environments inhibit expression of VEGF mRNA, but VEGF expression/secretion is accentuated when the hyperoxia environment is relieved [14]. This occurs at the late pregnancy stage in order to meet the needs of the rapid developments in various tissues and organs. Thus, there in need for high VEGF levels, but with the continuous improvements in the development of various tissues and organs, VEGF levels are gradually reduced [15]. The important role of VEGF in ROP has been demonstrated.

It is known that IGF-1 is a broad-spectrum growth-promoting factor that increases the synthesis and activity of VEGF by binding to the IGF-1 receptor. This promotes the migration, differentiation, and maturation of retinal vascular endothelial cells, and ultimately induces vascular lumen formation. It has been reported that IGF-1 levels are significantly reduced in ROP. Moreover, IGF- 1 plays a very important role in the development of the retina and brain [16].

In the present study, IGF-1 and VEGF levels in $A G$ and the hyperoxia rhlGF-1 group were markedly elevated, when compared with corresponding values in HS mice on days 11 and 15. On day 20, IGF-1 levels in the air and the hyperoxia rhIGF-1 groups were markedly increased, relative to hyperoxia mice, and the VEGF level was markedly less than that in the hyperoxia mice. However, on days 11, 15 and 20, IGF-1 in the control and hyperoxia rhIGF-1 groups were comparable. The levels of VEGF in the hyperoxia rhlGF-1 group were significantly lower than those in the control group on days 11 and 15. Serum VEGF in the hyperoxia rhlGF-1 and control groups were comparable on day 20 . These results indicate that early supplementation with exogenous rhIGF-1 results in marked increases in serum IGF-1 and retinal IGF-1 levels. At the same time, IGF-1 promoted VEGF production and retinal VEGF expression, and significantly enhanced the development of retinal blood vessels, thereby reducing the formation of new blood vessels.

\section{CONCLUSION}

Early supplementation with exogenous rhIGF-1 in the treatment of oxygen-induced ROP in a mouse model produces desirable outcomes. It promotes the growth and development of ROP mice, and reduces retinal neovascularization. Moreover, it has a positive effect on the expressions of IGF-1 and VEGF. Further investigations are required to determine its suitability for the clinical management of ROP.

\section{DECLARATIONS}

\section{Conflict of interest}

No conflict of interest is associated with this work.

\section{Contribution of authors}

This work was done by the authors named in this article and the authors accept all liability resulting from claims which relate to this article and its contents. Danying Wang designed the study and interpreted the results. Xiangjun $\mathrm{Wu}$, Hui $\mathrm{Ye}$, Qiao Cai, Yuanxiang Ke, Danying Wang collected data and drafted the manuscript. Xiangjun Wu performed the experiments.

\section{Open Access}

This is an Open Access article that uses a funding model which does not charge readers or their institutions for access and distributed under the terms of the Creative Commons Attribution License (http://creativecommons.org/licenses/by/ 4.0) and the Budapest Open Access Initiative (http://www.budapestopenaccessinitiative.org/rea d), which permit unrestricted use, distribution, 
and reproduction in any medium, provided the original work is properly credited.

\section{REFERENCES}

1. Chen $Y$, Xun $D$, Wang $Y C$, Wang $B$, Geng $S H$, Chen $H$, $L i Y T, L i X X$. Incidence and risk factors of retinopathy of prematurity in two neonatal intensive care units in North and South China. Chin Med J (Engl) 2015; 128(7): 914918.

2. Wang GQ, Gao XH. Effects of intravitreal injection of ranibizumab on VEGF, IGF-1 and GLU in children with retinopathy of prematurity. Northwestern J National Def Med 2017; 1(6): 356-360.

3. Yan L, Han M, Zhao KX. Effect of metformazole-induced low concentration serum IGF-1 on neonatal rat retinal neovascularization induced by hyperoxia. Chin $J$ Ophthalmol 2010; 46(7): 585-589.

4. Sun XP, Zhu YS, Liu C. Effects of insulin-like growth factor-1 on hypoxia-inducible factors and brain edema around hematoma in rats. Med Animal Control 2016; 2(8): 880-882

5. Jin YA, Zhao YK, Jin ZY, Qi HF, Mokhles WG, Gong MH. Effect of insulin-like growth factor-1 on apoptosis induced by hyperoxia in $A 549$ cells. Chin J Contemp Pediatr 2016; 15(6): 490-493.

6. World Health Organization. Principles of laboratory animal care. WHO Chron 1985; 39: 51-56

7. $X u W Q$, Wang YS. The role of Toll-like receptors in retinal ischemic diseases. Int $\mathrm{J}$ Ophthalmol (English Ed) 2016; 9(9): 1343-1351.

8. Li WL, Xiao SY, Wang L, Liu XH, He L, Wang XZ, Zhang $L$. Effects of resveratrol on the expression of retinal $B$ cell leukemia protein 2 and vascular endothelial growth factor induced by oxygen in rats. Chin J Optom Vis Sci 2017; 11(5): 360-363.

9. Wu N, Huang ML. Establishment of an improved oxygeninduced animal model of retinopathy in prematurity. Chin J Biol Prod 2015; 25(8): 985-988.

10. Saito $Y$, Uppal A, Byfield G, Budd S, Hartnett ME. Activated $N A D(P) H$ oxidase from supplemental oxygen induces neovascularization independent of VEGF in retinopathy of prematurity model. Invest Ophthalmol Vis Sci 2018; 49(4): 1591-1598.

11. $X u H B$, Chen XL. Study on the effect of oxygen inhalation on neonatal rat retina. Ophthalmol Res 2015; 22: 494497.

12. Kwinta P, Bik-Multanowski M, Mitkowska Z, Tomasik T, Pietrzyk JJ. The clinical role of vascular endothelial growth factor (VEGF) system in the pathogenesis of retinopathy of prematurity. Graefes Arch Clin Exp Ophthalmol 2018; 246(10): 1467-1475.

13. Shibuya M. Vascular Endothelial Growth Factor (VEGF) and Its Receptor (VEGFR) Signaling in Angiogenesis: A Crucial Target for Anti- and Pro-Angiogenic Therapies. Genes Cancer 2011; 2(12): 1097-105.

14. Zhang $X Z$, Jiang JB, Luo $X Q$, Huang $S Q$, Yang J, Li JQ, Lin $Q X$. Effect of vascular endothelial growth factor small interfering RNA (siRNA) on retinal microvascular endothelial cells under hypoxia condition in vitro. Zhonghua Er Ke Za Zhi 2009; 47(6): 457-461.

15. Han YL. Role of vascular endothelial growth factor and insulin-like growth factor-1 in retinopathy of prematurity. Int J Pediatr 2016; 41: 590-593.

16. Smith LEH. IGF-1 and Retinopathy of Prematurity in the Preterm Infant. Neonatol 2015; 88(3): 237-244. 